\title{
Acidosis and severe megaloblastic anaemia
}

\author{
IM FRANKLIN, * PBA KERNOFF, $†$ D ISHERWOOD, J LEEK, DB MORGAN \\ From the Department of Haematology and University Departments of Medicine and Chemical Pathology, The \\ General Infirmary, Leeds LS1 3EX
}

SUMMARY Ten patients with severe megaloblastic anaemia were studied to investigate whether the causative metabolic defects might predispose them to lactic or other acidosis. One patient had compensated acidosis with hyperlactataemia before treatment but there were obvious causes other than anaemia. No other patient developed an acidosis. Neither anaemia per se nor the metabolic defects of vitamin $B_{12}$ or folic acid deficiency are likely to cause clinically significant lactic acidosis or hyperlactataemia.

The pathogenesis of megaloblastic anaemia is well understood and effective treatment is readily available. Despite this the mortality in severe cases (PCV $<0.25$ ) is considerable, ${ }^{\prime}$ and many patients die suddenly and unexpectedly. ${ }^{2}$ The fall in plasma potassium after treatment has been suggested as a cause,,$^{13}$ and an additional or alternative factor might be the presence of an acidosis, particularly lactic acidosis, as suggested by the report of Coronato and Cohen. ${ }^{4}$ They described a patient with severe pernicious anaemia and lactic acidosis, although the concentration of blood lactate $(5 \cdot 2$ $\mathrm{mmol} / \mathrm{l}$ ) does not fully explain the degree of acidosis (arterial pH 7.25; anion gap $31.5 \mathrm{mmol} / \mathrm{l}$ ), and other anions may have been involved. Because of compensatory mechanisms anaemia has a minimal effect on blood lactate. ${ }^{5-7}$ In vitamin $B_{12}$ deficiency, however, the metabolic defects might cause accumulation of lactate and methylmalonic acids and so contribute to an acidosis.

This study was carried out to assess the frequency of acidosis, including lactic acidosis, in patients with severe megaloblastic anaemia before and after treatment.

\section{Patients and methods}

PATIENTS

Ten newly-presenting patients with megaloblastic anaemia were studied. There were five men and five

\footnotetext{
*Present address: Department of Clinical Haematology, University College Hospital, Gower Street, London WC1E 6AU.

$\dagger$ Present address: Academic Department of Haematology, Royal Free Hospital, London NW3 2QG.
}

Accepted for publication 3 February 1982 women; ages ranged from 59-80 yr (median $71 \mathrm{yr}$ ). All had haemoglobin concentrations less than $6 \mathrm{~g} / \mathrm{dl}$ $(\mathrm{PCV}<0.2)$ and a megaloblastic bone marrow picture. Five patients had pernicious anaemia (PA), four had folic acid deficiency and one (patient 7), vitamin $\mathrm{B}_{12}$ deficiency secondary to ulcerative colitis.

With the exception of patient 10 , who was admit-o ted in a shocked state with ECG evidence of myocardial infarction, and who died on the day after admission, none of the patients had evidence of cardiac failure, pulmonary oedema or peripheral circulatory failure at any time during the course of the study.

\section{INVESTIGATIONS}

Venous blood was obtained daily from the patients for the first seven days in hospital, treatment commencing on day 1 after sampling. A further sample was obtained at least one month later.

Haematological tests were carried out using standard methods. Plasma electrolytes, urea, creatinine, phosphate, calcium, aspartate aminotransferase and glucose and urinary phosphate were measured using a Vickers M300 Multichannel Analyzer. The plasma anion gap $(\mathrm{mmol} / \mathrm{l})$ was calculated as $(\mathrm{Na}+\mathrm{K})-$ $\left(\mathrm{Cl}+\mathrm{HCO}_{3}\right)$. Blood lactate, pyruvate, 3-hydroxybutyrate and acetoacetate were measured using an LKB 8600 Reaction Rate Analyzer according to the methods of Wootton ${ }^{8}$ and Annan. ${ }^{9}$ On day 0 only, arterial $\mathrm{pH}, \mathrm{PCO}_{2}$, and $\mathrm{PO}_{2}$, were measured using a Corning $165 \mathrm{pH} / \mathrm{Blood}$ Gas Analyzer.

Results are given as means \pm standard error of mean (SEM).

\section{Results}

All surviving patients responded to specific 
haematinic therapy. Patient 10 was admitted in severe circulatory and renal failure, and was hyperglycaemic (plasma urea $30 \mathrm{mmol} /$, blood glucose 20 $\mathrm{mmol} / \mathrm{l}$ ). She had a compensated metabolic acidosis with anion gap $26 \mathrm{mmol} / \mathrm{l}$, bicarbonate $10 \mathrm{mmol} / \mathrm{l}$, and arterial pH 7.49, $\mathrm{PCO}_{2} 2.5 \mathrm{kPa}, \mathrm{PO}_{2} 11.2 \mathrm{kPa}$, giving a calculated non-respiratory $\mathrm{pH}$ of $7 \cdot 24 .^{10}$ Blood lactate was $11.8 \mathrm{mmol} / \mathrm{l}(\mathrm{NR}=0.3-2.3$ $\mathrm{mmol} / \mathrm{l})$ and pyruvate $590 \mu \mathrm{mol} / \mathrm{l}(\mathrm{NR}=57-107$ $\mathrm{mmol} / \mathrm{l}$ ) with slightly raised lactate:pyruvate (L:P) ratio of $20(\mathrm{NR}=5-15 \mathrm{mmol} / \mathrm{l})$. Before death, and with treatment, these values had fallen to 3.6 $\mathrm{mmol} / \mathrm{l}, 200 \mu \mathrm{mol} / \mathrm{l}$ and 18 respectively. Accumulation of lactate seemed to be the principal cause of acidosis in this patient.

Patient 7 had normal lactate and pyruvate concentrations when first tested but these rose to sharp peaks of $10.3 \mathrm{mmol} / \mathrm{l}$ and $960 \mu \mathrm{mol} / 1$ respectively on day 4. His plasma bicarbonate concentration fell slightly to $19 \mathrm{mmol} / \mathrm{l}$ at this time but the L:P ratio remained normal.

Five patients had mild hypokalaemia after treatment, and three were given potassium supplements. Patient 6 had mild chronic renal failure and marginally low plasma bicarbonate. All other patients had normal values for plasma sodium, chloride, urea and creatinine and all patients except number 10 had a normal anion gap throughout, with normal arterial blood $\mathrm{pH}$ on admission.

\section{Discussion}

Severe anaemia per se is unlikely to cause either lactic acidosis or more than minimal raised concentration of blood lactate $e^{5-7}$ and reported associations between anaemia and lactic acidosis have generally been observed in patients with coincident circulatory failure. "An exception is Coronato and Cohen's patient (1969), ${ }^{4}$ who had pernicious anaemia and presented with a severe acidosis but little evidence of circulatory failure. The blood lactate concentrations do not fully account for the acidosis, however. The interesting possibility has been raised that there might be specific metabolic defects in $\mathrm{B}_{12}$ deficiency which could cause such an acidosis. ${ }^{7}$ The results of this study do not support this hypothesis. Only one patient had hyperlactataemia before treatment and there was an obvious cause other than the megaloblastic anaemia - that is, shock and diabetes. No other patient had lactic acidosis or a significantly abnormal arterial blood $\mathrm{pH}$.

The raised concentrations of lactate and pyruvate found in patient 7 also seem unlikely to be causally related to Vitamin $B_{12}$ deficiency or anaemia since treatment with hydroxocobalamin had been given for three days before the lactate concentration rose. The cause of the hyperlactataemia in this patient was not apparent. He was taking sulphasalazine $\mathbf{5 0 0}$ mg twice daily for his ulcerative colitis, which was thought to be in remission, and felt well throughout his admission. While the salicylate content of the sulphasalazine might, theoretically, contribute to an acidosis we are unaware of any evidence relating sulphasalazine to raised lactate concentrations. Patient 7 would seem to have shown an example of a phenomenon noted by Huckabee ${ }^{5}$-occasional inexplicable increases in blood lactate occurring in rested, hospitalised patients. We have found no evidence, therefore, to suggest that the specific metabolic defects of Vitamin $B_{12}$ or folic acid deficiency may cause either hyperlactataemia or lactic acidosis and we think it unlikely that such mechanisms contribute to increased early mortality. If lactic acidosis is detected in a patient with severe megaloblastic anaemia it will be due to a cause other than the anaemia itself or the metabolic effects of the deficiency.

We wish to thank Drs BE Roberts and JA Child for their assistance with this project.

\section{References}

' Lawson DH, Murray RH, Parker JWL. Early mortality in the megaloblastic anaemias. $Q J$ Med 1972;41:1-14.

${ }^{2}$ Lawson DH, Parker JLW. Deaths from severe megaloblastic anaemia in hospitalised patients. Scand $J$ Haematol 1976;17:347-52.

${ }^{3}$ Hesp R, Chanarin I, Tait CE. Potassium changes in megaloblastic anaemia. Clin Sci Mol Med 1975;49:77-9.

4 Coronato A, Cohen AB. Lactic acidosis secondary to pernicious anaemia. Ann Intern Med 1969;70:77-80.

${ }^{5}$ Huckabee WE. Abnormal resting blood lactate. 1. The significance of hyperlactatemia in hospitalized patients. Am J Med 1961;30:833-9.

- Seibert DJ, Ebaugh FG. Assessment of tissue anoxemia in chronic anaemia by the arterial lactate/pyruvate ratio and excess lactate formulation. J Lab Clin Med 1967;69:177-82.

' Cohen RD, Woods HF. Clinical and biochemical aspects of lactic acidosis. Oxford: Blackwell Scientific Publications, 1976.

'Wootton IDP. Microanalysis in medical biochemistry. 4th ed. London: Churchill, 1964.

'Annan W. The determination of lactate, pyruvate, D3-hydroxybutyrate and acetoacetate in blood using an enzyme reaction rate analyser. MSc thesis. University of Leeds, 1974.

${ }^{10}$ Stoker KB, Kappagoda CT, Snow HM, et al. The assessment of acid-base disturbance in man by the use of carbon dioxide titration curves. Clin Sci Mol Med 1975;48:133-8.

" Geerken RG, Gibbons RB. Lactic acidosis associated with iron deficiency anaemia. JAMA 1972;211:292-3.

Requests for reprints to: Dr IM Franklin, Department of Clinical Haematology, University College Hospital, Gower Street, London WC1E 6AU, England. 